\title{
Hochpräziese Stümpfe
}

Mirapont ist ein heller, hoch präziser Spezialkunststoff für Stümpfe, Modelle und Zahnkränze. Der Spezialkunststoff (Polyurethan) ermöglicht eine äußerst harte, genaue und detailgetreue Reproduktion des Zahnbestands bzw. der anatomischen Verhältnisse des Patienten.

Die beiden Komponenten A (Polyol) und B (Isocyanat) werden im Verhältnis 1:1 in nur $30 \mathrm{~s}$

ange-

rührt. Be-

reits nach

ca. $90 \mathrm{~min}$

kann ent-

formt, ge-

sägt und

beschlif-

fen wer-

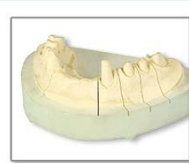

den. Das

leicht fließende, äußerst hitzebeständige (ca. $120^{\circ} \mathrm{C}$ ) und kantenstablie Material eignet sich für alle Abformmaterialien (Silikon, Alginat, reversiblem Hydrokolloid u. Thermoplast). Die Schrumpfung beträgt lediglich 0,02 \% (basierend auf einer linearen Gußform von 10 x 0,5 x $2 \mathrm{~cm}$ ). Am Abformmodell können mit dem Material (Spezialausblockmaterial) nicht benötigte Partien ausgeblockt werden (Materialeinsparung). Beim Beschleifen des Materials gibt es keine Span - und Splitterentwicklung.

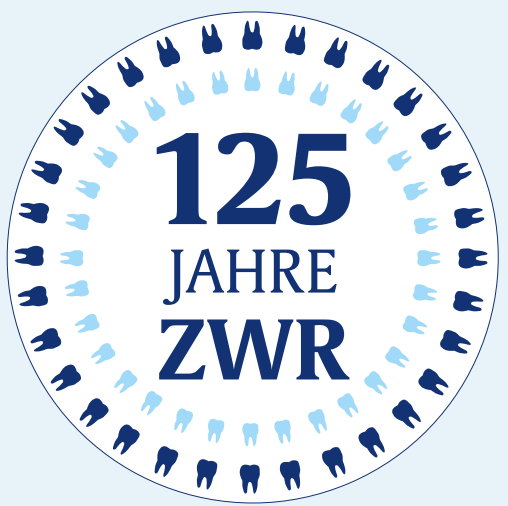

